\title{
Human Brain Regions Involved in Heading Estimation
}

\author{
H. Peuskens, ${ }^{1}$ S. Sunaert,, ${ }^{2}$ P. Dupont, ${ }^{3}$ P. Van Hecke, ${ }^{2}$ and G. A. Orban ${ }^{1}$ \\ ${ }^{1}$ Laboratorium voor Neuro- en Psychofysiologie, KULeuven, Medical School, Campus Gasthuisberg, B-3000 Leuven, \\ Belgium, ${ }^{2}$ Afdeling Radiologie, UZ Gasthuisberg, B-3000 Leuven, Belgium, and ${ }^{3}$ Centrum voor Positron Emissie \\ Tomografie, Departement Nucleaire Geneeskunde, UZ Gasthuisberg, B-3000 Leuven, Belgium
}

\begin{abstract}
Observer motion in a stationary visual environment results in an optic flow pattern on the retina, which in simple situations can be used to determine the direction of self motion or heading. The present study, using positron emission tomography (PET) and functional magnetic resonance imaging (fMRI), investigated the human cerebral activation pattern, elicited when subjects viewing a ground plane optic flow pattern actively judged heading. Several successive experiments controlled for visual input, visuospatial attention, and motor response effects. Results in-
\end{abstract}

dicate that the network specifically involved in heading consists of only two motion sensitive areas: human MT/N5+, including an inferior satellite, and dorsal intraparietal sulcus area (DIPSM/ L), predominantly in the right hemisphere, plus a dorsal premotor region bilaterally. These results suggest possible homologies with the dorsal part of the medial superior temporal area and area $7 \mathrm{a}$ in the monkey.

Key words: functional imaging; visual cortex; motion; attention; optic flow; discrimination
Locomotion of an observer through the environment causes a global streaming of the visual field on the retina known as optic flow. Optic flow contains information about the threedimensional (3D) layout of the environment and about the relative motion between the observer and his environment. In a stationary environment, the optic flow pattern can be used by the observer to estimate the direction of self-motion or heading (Gibson et al., 1955). In the simplest case of observer translation without confounding eye or head movements (Regan and Beverly, 1982; Warren et al., 1988; Royden et al., 1992; Crowell et al., 1998), direction of self-motion corresponds to the focus of expansion (FOE) of the optic flow field. In this case, heading estimation is thought to rely on higher-order motion analysis in the cerebral cortex, whereas in the case of eye movements additional signals are needed.

Primate studies have implicated a number of cortical areas in the processing of optic flow stimuli. Converging lines of evidence point to the dorsal part of the medial superior temporal area (MSTd), a satellite of MT/V5, as playing an important role. Compared with MT/V5, the best known motion sensitive area (Dubner and Zeki, 1971), MSTd contains large receptive field cells, selective for optic flow components such as rotation, expansion, and contraction (Saito et al., 1986; Lagae et al., 1994), and for combinations of translation with rotation and/or expansion and contraction (Duffy and Wurtz, 1991; Orban et al., 1992;

\footnotetext{
Received Sept. 11, 2000; revised Dec. 19, 2000; accepted Jan. 16, 2001.

This work was supported by the Fund for Scientific Research-Flanders (G.0358.98 and G.0202.99), the Queen Elisabeth Medical Foundation, and IUAP (4/22). H.P. and S.S. are Research Assistants and P.D. is a Postdoctoral Fellow of the Fund for Scientific Research-Flanders (FWO-Vlaanderen) (Belgium). We are grateful to Y. Celis, P. Kaeyenberg, and G. Meulemans for technical assistance; to P. Falleyn and M. De Paep for help with software programming; to G. Bormans, S. Vleugels, V. Van den Maegdenbergh, L. Verhaegen, K. Stessel, P. Pitschon, T. de Groot, and M. Bex for their assistance during PET scanning; to E. Beatse and I. Faillenot for their assistance with fMRI data processing; to S. Raiguel and W. Warren for their comments on this manuscript; and to L. Cornette for invaluable discussions.

Correspondence should be addressed to Dr. G. A. Orban, Laboratorium voor Neuro- en Psychofysiologie, KULeuven, Medical School, Campus Gasthuisberg, Herestraat 49, B-3000 Leuven, Belgium. E-mail: Guy.Orban@Med.Kuleuven.Ac.Be. Copyright (C) 2001 Society for Neuroscience $0270-6474 / 01 / 212451-11 \$ 15.00 / 0$
}

Graziano et al., 1994; Lappe et al., 1996). Bradley et al. (1996) showed that neurons in MSTd responded selectively to an expansion focus in a specific part of the visual field and that this selective region shifted during eye movements to compensate for retinal focus shifts. Finally, linking neurophysiological data with the behavioral level, Britten and van Wezel (1998) demonstrated that microstimulation in area MSTd interfered with a heading task in macaque monkeys.

MSTd projects to area $7 \mathrm{a}$ in the inferior parietal lobule, the ventral intraparietal area, and the anterior superior temporal polysensory (STP) area in the superior temporal sulcus (Andersen et al., 1990; Boussaoud et al., 1990; Baizer et al., 1991). These areas contain cells selective for optic flow (Sakata et al., 1985; Andersen et al., 1990; Schaafsma and Duysens, 1996; Siegel and Read, 1997a; Anderson and Siegel, 1999).

To date, human imaging data specifically concerned with the processing of optic flow stimuli are limited and involve only passive viewing conditions. De Jongh et al. (1994) compared viewing of an optic flow field with a random motion field and observed no differential activity in human (h)MT/V5+ but described activation in right area V3, right superior parietal lobule, and bilateral fusiform gyrus. In the current study, an active heading task was used to study the neural correlates of optic flow processing. The active task allowed for strict control of subjects' behavior and, more importantly, was expected to reveal a more specific activation pattern attributable to the task-dependent nature of visual processing (Dupont et al., 1993; Cornette et al., 1998; Orban and Vogels, 1998).

\section{MATERIALS AND METHODS}

Subjects. Nine (all male) and 13 subjects ( 11 male) participated in a PET study and in one of three functional magnetic resonance imaging (fMRI) experiments (fMRI1, -2, and -3), respectively. All subjects were righthanded, aged between 20 and 25 years, had no neurological history, and were drug free. They had normal or corrected (contact lenses) to normal vision. Studies were approved by the ethical committee of the KULeuven Medical School, and written informed consent was obtained from each subject in accordance with the Helsinki Declaration.

Eye movements were monitored during scanning using EOG in the 
PET camera and the OBER2 system (Permobil MeditechAB) in the MR scanner (Sunaert et al., 1999).

Basic stimulus layout and tasks. Stimuli were generated with a PC using a TIGA-diamond (Salient AT3000) graphics card. In the PET experiment they were displayed on a high resolution color screen (Philips brilliance2120) mounted above the scanner bed at an angle of $52^{\circ}$ relative to the horizontal, at a distance of $114 \mathrm{~cm}$. In the fMRI experiments, stimuli were projected by means of an LCD projector (Sharp GX-3800, $640 \times 480$ pixels, $60 \mathrm{~Hz}$ refresh) onto a translucent screen in the bore of the magnet $30 \mathrm{~cm}$ from the subject's eyes.

The stimulus configuration, measuring $16 \times 12$ visual degrees, included a red fixation point in the center of the screen, two peripheral red dots above the visual horizon, and a ground plane, sprinkled with 50 white dots (Fig. 1). The ground plane dots underwent either continuous or intermittent expanding motion, with dots accelerating from the FOE toward the edge of the screen (speeds ranging from $3.75^{\circ} / \mathrm{sec}$ to $7.5^{\circ} / \mathrm{sec}$ ). Flow dots had a fixed size, lifetimes of random duration (between 83 and $1500 \mathrm{msec}$ ), and they were regenerated at random positions, maintaining constant dot density over the ground plane. These conditions have been reported to allow high accuracy heading estimation (Warren et al., 1988).

In every 900 msec trial of the PET experiment, the focus of expansion was shifted laterally for a period of $200 \mathrm{msec}$ at randomized onset times. In addition, either of the two peripheral red dots dimmed for $200 \mathrm{msec}$ in one of two trials. Subjects attended to the shift of the expansion focus in the heading task and to the dimming of the static peripheral dots in the dimming condition (dimming static). During the interval between subsequent FOE shifts (700 $\mathrm{msec}$ on average), the ground plane dots moved radially from the screen center in the continuous flow stimuli but remained stationary in the intermittent flow stimuli. In fMRI1, we replicated the two tasks for the continuous flow stimuli and included a fixation condition in which subjects passively viewed the central fixation point on an empty background. In fMRI2 and fMRI3, we used an additional control condition, in which the continuous flow dots were dimmed at random times for a period of $200 \mathrm{msec}$ in one of two trials (dimming flow). In each experiment, visual input was equal across behavioral tasks (Fig. 1).

Subjects were required to maintain fixation on the central fixation point throughout the entire experiment. In the heading condition, they identified left or right shifts in focus of expansion by pressing left or right push buttons within $600 \mathrm{msec}$. In the dimming conditions, subjects detected dimming of either of the two red dots above the horizon (dimming static) or of the flow dots (dimming flow) by pressing both keys within a $400 \mathrm{msec}$ response window. Thus, the total number of key presses was equal in heading and dimming tasks, whereas the number of decisions to press in the dimming conditions was half that in the heading conditions. Motor response was manipulated to be identical in the heading and the dimming flow conditions, but only in the third fMRI experiment.

The stimulus was explicitly designed to induce subjects to use the global motion pattern rather than local motion cues in their heading judgements: dots were only sparsely sprinkled over the ground plane, had limited and random lifetimes, and were regenerated at random locations. However, as noted before (Warren and Kurtz, 1992; Britten and van Wezel, 1998), this display contains a possible confound because the direction of the FOE shift covaries with the direction of motion of dots directly below the fixation point. Therefore, a central area of 1.5 visual degrees around the fixation point was blanked out. In addition, we performed a psychophysical control experiment which confirmed that subjects did not base their heading judgements on local dot movement. In this experiment, the normal stimulus configuration was presented in most trials, but in a randomly occurring $10 \%$ of trials, only 1 of the 50 flowing dots, rather than the complete pattern, was displayed during the FOE deviation. This single dot appeared either centrally, directly under the fixation point, or peripherally, under one of the lateral red dots (Fig. 2, left panel ). Five subjects, fully trained in the heading task, performed five successive sessions of 200 trials each. Performance in the normal heading trials was high in all sessions, but very poor in the first sessions for both central and peripheral single-dot conditions (Fig. 2, middle panel). Concurrently, significantly longer response times were recorded in the singledot conditions (Fig. 2, right panel). After a number of sessions, performance increased for the central dot condition, which contains the most information, but did not reach the level of the normal heading task. Performance remained at chance level for the peripheral dot condition. In summary, these data demonstrate that the subjects used more than
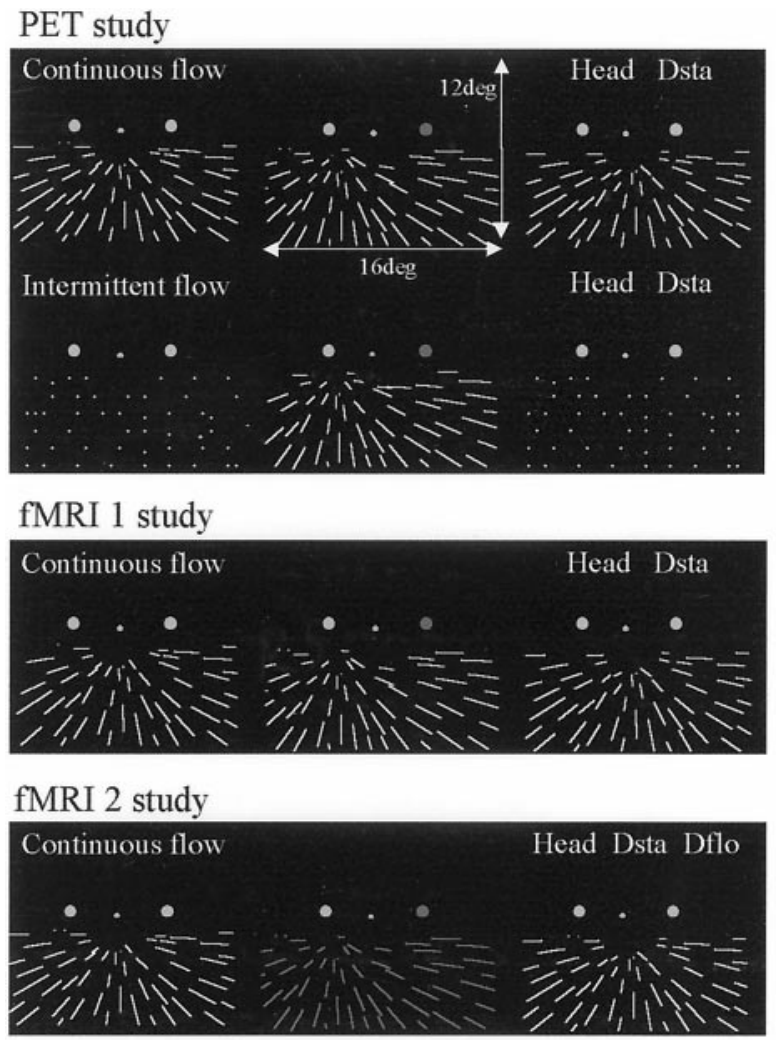

fMRI 3 study

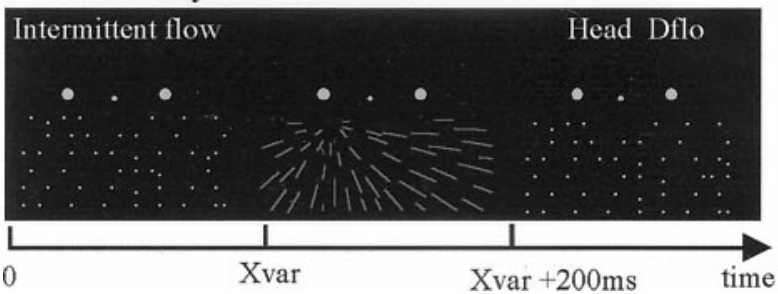

Figure 1. Schematic representation of the stimuli and trial types used in the PET, fMRI1, -2 , and -3 experiments. All stimulus displays included a central fixation point, two peripheral dots on the horizontal meridian, and a ground plane dot field. The fixation target and peripheral dots were red in the actual experiments. In all experiments, a trial included a $200 \mathrm{msec}$ lateral displacement of the FOE, dividing the trial into three epochs. The stimulus display for each of these epochs is shown from left to right. Lines in the ground plane indicate moving dots; points indicate static dots. In PET, fMRI1, and fMRI2, one in two trials included a $200 \mathrm{msec}$ dimming of one of the peripheral red dots; in fMRI2 and fMRI3, one in two trials featured a $200 \mathrm{msec}$ dimming of the flow points. For illustration purposes dimming is shown in all trials. Trial duration was $900 \mathrm{msec} . X_{\mathrm{var}}$ is the variable onset time for the FOE displacement or dimming in a trial; the type of flow is indicated in the top left corner, and the different conditions are indicated in the top right corner. Head, Heading; Dsta, detection of dimming of static peripheral dots; $D$ flo, detection of dimming of flow dots.

individual dot motion cues in the normal heading trials, implying that they attended to the global flow pattern.

The stimulus display contains a second possible confound, as suggested by one of the anonymous reviewers. The fraction of flow dots, with a lifetime exceeding $200 \mathrm{msec}$, will change their direction at the onset of the FOE shift in the continuous flow conditions. It should be noted that this change in dot trajectory did not occur in the intermittent flow conditions, underscoring the importance of the comparison of these conditions, as done in the initial PET experiment.

All subjects were trained in two $1 \mathrm{hr}$ training sessions before scanning. The aim of these sessions was to familiarize the subjects with the tasks, to obtain a stable performance, and to assess, for each individual subject, 

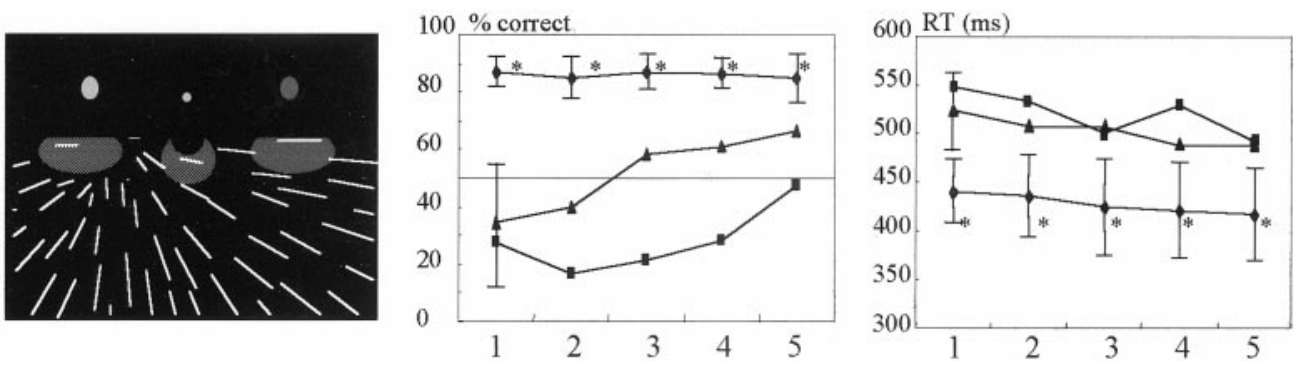

Figure 2. Psychophysical control experiment. Left panel, Marked areas in the display indicate the three locations where single dots were presented, either centrally or peripherally. Middle and right panels, Percentage correct responses (middle) and reaction times (right) for three types of stimulus displays ( $\bullet$, normal ground plane; $\boldsymbol{\Lambda}$, central single dot; $\mathbf{\square}$, peripheral single dot) plotted as a function of session number. ${ }^{*} p<0.05$, Student's paired $t$ test, for normal ground plane versus each other condition. the shift of the FOE in the heading task and the luminance change in the dimming conditions required to obtain a performance of $80 \%$ correct. These settings were then used during scanning to equate performance levels in the different tasks.

PET experiment. In the PET experiment, images were acquired with a high resolution PET scanner (Siemens-CTI, ECAT Exact HR+) in 3D mode, with septa retracted, using the $\mathrm{H}_{2}{ }^{15} \mathrm{O}$ method (Fox et al., 1986). Subjects were immobilized using a foam head holder (Smither Medical Products, Akron, $\mathrm{OH}$ ). A transmission scan was obtained to correct for attenuation. Subjects received a small bolus injection of $300 \mathrm{mBq} \mathrm{H}_{2}{ }^{15} \mathrm{O}$ over $12 \mathrm{sec}$ at the beginning of each task. The emission scan was started when radioactivity reached the brain and lasted $60 \mathrm{sec}$.

Conditions were organized in a $2 \times 2$ factorial design experiment with task and stimulus as factors: subjects performed either the heading task or the dimming static task; optic flow in the stimulus was either continuous or intermittent (Fig. 1). Each of the four experimental conditions was repeated three times in every subject, amounting to 12 scans per subject.

fMRI experiments. The fMRI data were acquired in a 1.5 Tesla magnet (Siemens VISION) using blocked designs. Sagittal anatomical images were acquired before each functional imaging session (3D MPRAGE, repetition time $(\mathrm{TR}) / \mathrm{echo}$ time $(\mathrm{TE})=11.4 / 4.4 \mathrm{msec}$, TI $300 \mathrm{msec}, \mathrm{FOV}$ $256 \times 256 \mathrm{~mm}^{2}, 256 \times 256$ matrix, $160 \mathrm{~mm}$ slab thickness, 128 sagittal partitions). A functional imaging series consisted of 120 gradient-echo echo planar imaging whole-brain scans, acquired every 4 sec [TE 40 msec, flip angle $90^{\circ}$, FOV $200 \times 200 \mathrm{~mm}^{2}, 32$ noncontiguous axial slices (sagittal slices in fMRI3), $4 \mathrm{~mm}$ thickness; $0.4 \mathrm{~mm}$ slice gap]. Conditions were presented in blocks of 10 images in fMRI 1 and fMRI2, and in blocks of 8 images in fMRI3. In a time series, the number of images and replications per condition depended on the number of different conditions included in the experiment. The condition order was pseudorandomized; short, prerecorded, oral commands signaled switches between conditions. In every subject, each time series was repeated six times.

Each time series included a "fixation" condition as a baseline reference. In the first fMRI experiment (fMRI1: four subjects) two of the original conditions (heading and dimming static with continuous flow) (Fig. 1) from the PET study were replicated together with the fixation condition. In the second fMRI study (fMRI2: four subjects), the dimming flow condition was introduced along with heading, dimming static, and fixation. This extra task was included to match visuospatial attention in the control task more closely to that of the heading task, which has been shown to involve global computation (Royden and Hildreth, 1999). Continuous flow stimuli were used.

Finally, in the third fMRI experiment (fMRI3: five subjects), a new $2 \times 2$ factorial design was used. The first factor was a task with two levels: heading and detection of flow dots dimming. The second factor was the required motor response with two levels: left/right keys and both keys/no response. In heading-"left/right" (L/R) conditions subjects pressed either the left or right key for the matching heading direction; in the dimming flow $-\mathrm{L} / \mathrm{R}$ conditions they pressed the right key when dots dimmed and the left for no dimming. In the heading-"both keys" conditions, subjects responded by pressing both keys when heading was toward the right and no key when heading deviation was to the left; in the dimming flow-both keys, they pressed both keys when dimming occurred and no key when there was no dimming. In fMRI3, intermittent flow stimuli were used.

In all fMRI subjects, two additional time series were acquired in which passive viewing of a moving $\left(7^{\circ}\right.$ diameter, $6^{\circ} / \mathrm{sec}$, eight random directions) random texture pattern alternated every 10 images with the viewing of the same but stationary pattern. These conditions were identical to those described by Sunaert et al. (1999) and were used to localize motion responsive areas, more specifically hMT/V5+.

Data analysis. PET and fMRI data were analyzed with SPM96 (Wellcome Department of Cognitive Neurology, London, UK). Preprocessing steps included realignment, co-registration of the anatomical images to the functional scans, and spatial normalization into a standard space (Talairach and Tournoux, 1988) using affine and nonlinear transformations. Functional images were spatially smoothed with a Gaussian kernel (16 $\mathrm{mm}$ full width at half-maximum for the PET analysis, $4 \mathrm{~mm}$ for the single subject fMRI analyses, and $8 \mathrm{~mm}$ for the group fMRI analyses). Global changes in CBF and BOLD signal for PET and fMRI, respectively, were removed by ANCOVA scaling; low-frequency drifts in the fMRI were removed by using an appropriate high-pass filter.

Condition effects were tested by applying appropriate linear contrasts to the parameter estimates for each condition, resulting in a $t$ statistic for every voxel, which constituted the statistical parametric maps (fixed effect analysis). Threshold was set at $p<0.05$ corrected for multiple comparisons for activation height. For activation extent, threshold was set to 0.5 in the PET and to 0.05 in the fMRI studies.

To combine information from the two last fMRI studies that included the final control task (dimming flow), we performed a conjunction analysis. This analysis allows the identification of those activation sites, which are jointly significant (and not significantly different) in a series of subtractions. Thus it reveals the activation sites common to two or more subtractions (Price and Friston, 1997). For this purpose the data set was reduced by creating an average image per session and per condition using the random effects toolkit (SPM97; Wellcome Department of Cognitive Neurology). These images were subsequently analyzed in a multistudy design, and the conjunction between the subtraction (heading - dimming flow) of fMRI2 and the main effect (heading-dimming flow) of fMRI3 was obtained. A similar analysis was also performed on the motion localizer scans.

\section{RESULTS}

\section{Behavioral data}

During scanning, average $(\mathrm{n}=22$ subjects $)$ FOE deviation in the stimulus was 3.8 visual degrees and task performance was close to $80 \%$ correct (Fig. 3). In the PET study, average (continuous + intermittent) heading performance did not differ significantly from average dimming performance (Student's $t$ test, $p=0.22$ ). A small but significant difference was observed between individual conditions [ANOVA; $\left.F_{(3,24)}=7.36 ; p<0.001\right]$. Post hoc analysis indicated that performance in the continuous heading condition differed from both that in the intermittent heading condition (Scheffé, $p<0.05$ ) and that in the continuous dimming static condition (Scheffé, $p<0.05$ ). However, these differences were not reflected in the imaging data, because direct comparison of continuous and intermittent heading conditions yielded no significant activation. In the fMRI studies, ANOVAs indicated that performance was closely matched among the conditions (fMRI1: $F_{(1,3)}=0.84, p=0.4$; fMRI2: $F_{(2,6)}=2.7, p=0.1$; fMRI3: $F_{(3,12)}=$ 2.7, $p=0.14$ ) (Fig. 3).

Subjects maintained fixation well during scanning. In the PET experiment, the average frequency of saccades was one per minute, and the average frequency of eye blinks was 2.2 per 


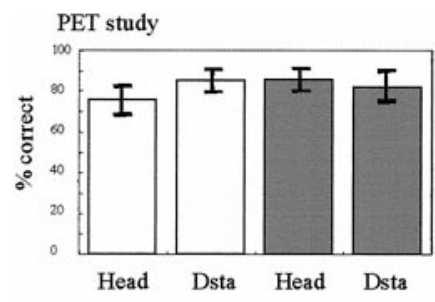

fMRI1 study
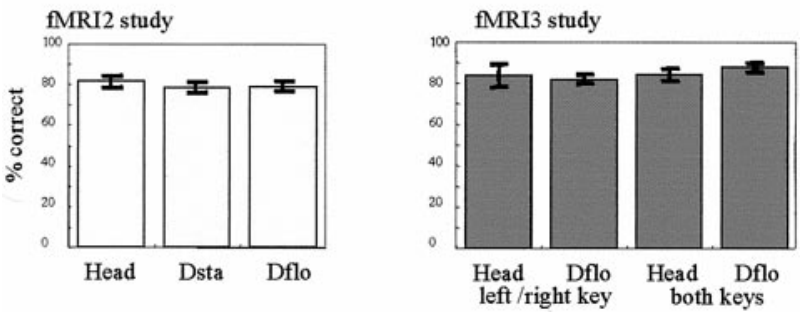

Figure 3. Performance in percentage correct responses for the different conditions in PET, fMRI1, -2, and -3 experiments. Error bars indicate SDs. Light gray bars, Continuous flow conditions; dark gray bars, intermittent flow conditions.

minute. Saccades and blinks were equally rare in the fMRI experiments. In none of the four experiments did the frequency of eye movements differ significantly among conditions (Friedman ANOVAs: all $p>0.1$ ).

\section{PET experiment}

The main effect of heading yielded strong activation of early visual areas, with the possible inclusion of hMT/V5+, of posterior parietal, and of dorsal premotor regions (Fig. 4, Table 1). In occipital cortex the subtraction (all heading - all dimming static) yielded extensive activation of the cuneus with local maxima in presumed V2 and V3a. This dorsal occipital activation corresponded to the known retinotopic representation of the inferior visual field (Sereno et al., 1995, Engel et al., 1997; DeYoe et al., 1996). The most anterior occipitotemporal local maxima were symmetrically located at $(-44,-80,4 ; Z=7.21)$ and $(40,-82,4$; $Z=5.29)$, somewhat posterior to the standard location of hMT/ V5+ (Zeki et al., 1991; Dupont et al., 1994; Tootell et al., 1995; Sunaert et al., 1999). Probing the subtraction with the coordinates of hMT/V5+ of Sunaert et al. (1999) yielded $Z$ scores of 5.46 ( $p<0.05$ corrected) and 3.18 ( $p<0.001$ uncorrected) for right and left hMT/V5+, respectively. In the superior parietal lobule, a bilateral activation was observed dorsally in the intraparietal sulcus (IPS), probably corresponding to DIPSM or DIPSL, two motion-responsive regions in the posterior intraparietal sulcus described by Sunaert et al. (1999). Finally, a number of posterior frontal regions, particularly the dorsal premotor regions bilaterally, and right-sided cerebellum were significantly activated.

The inverse subtraction (all dimming static - all heading) yielded significant activation sites located predominantly in left frontal lobe and left anterior and middle temporal lobe. Posterior sites included only a site in left inferior parietal lobule and another in left posterior cingulate sulcus.

There was no significant main effect of stimulus manipulation (all continuous-all intermittent motion stimuli and its inverse), indicating that irrelevant flow motion between the FOE deviations did not influence the activation pattern. Nor were the interactions between the two factors significant. Therefore, task effects were considered to be independent of stimulus effects. This indicates that the spurious cue present in the continuous
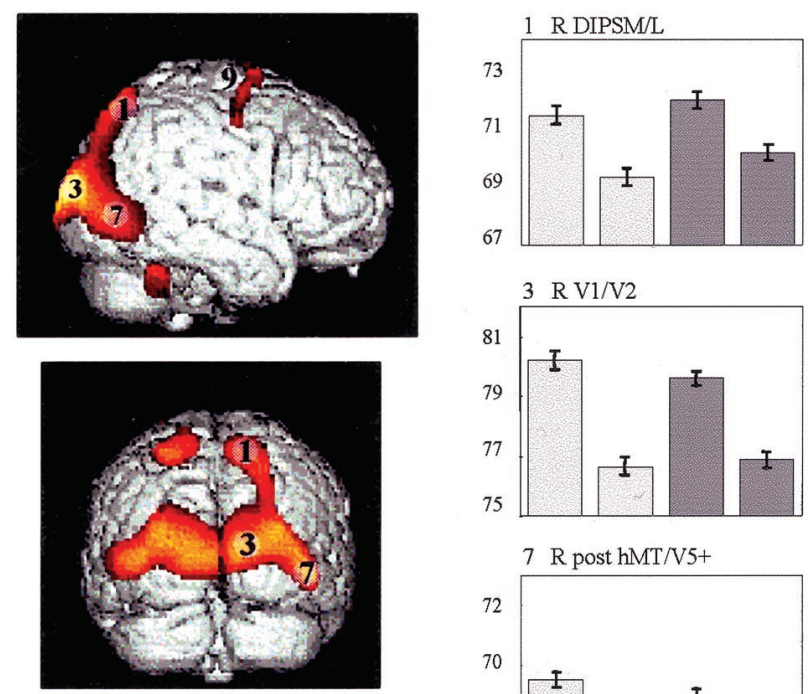

7 R post hMT/V5+

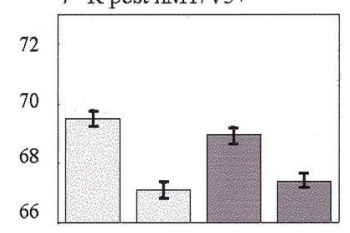

9 R dors Premotor

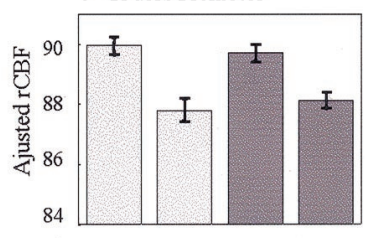

Head Dsta Head Dsta

Figure 4. Results of PET study. Left panels, Rendered images (right, posterior, and left view of standard brain) of the voxels reaching $p<0.001$ (see color code) in the main effect of task: all heading-all dimming static. Right panels, Activity profiles plotting adjusted rCBF for the four conditions in four regions of the right hemisphere. Light gray bars indicate continuous flow conditions; dark gray bars indicate intermittent flow conditions. Error bars indicate SEM. Numbers correspond to the sites listed in Table 1. Head, Heading; Dsta, dimming static.

flow conditions caused by the turning of the dots did not affect the results. It also made it possible to alternate between the continuous and intermittent flow conditions to study task effects in subsequent fMRI studies.

\section{fMRI1: involvement of hMT/V5+}

The first fMRI experiment was performed specifically to verify that hMT/V5 + is differentially active in the heading task compared with the dimming control task. Therefore, we localized hMT/V5 + for every subject and for the group in both hemispheres (Table 2, Moving - Stationary) by subtracting passive viewing of moving and stationary texture pattern. These coordinates were compared with those yielded by the comparison of the continuous heading and the dimming static tasks in the same subjects (Table 2, Heading - Dimming static). The agreement is excellent: the median difference in coordinates is small $(x=0, y=$ $1, z=2$, and $x=1, y=-1, z=2$ for right and left hMT/V5, respectively). Thus, this experiment demonstrates that hMT/ $\mathrm{V} 5+$ is specifically involved in heading.

\section{fMRI 2: equating spatial attention}

In the second fMRI experiment, a new control condition (dimming flow) was introduced in which spatial attention requirements were more closely matched to the heading task. Because a number of authors have reported effects of spatial attention on 


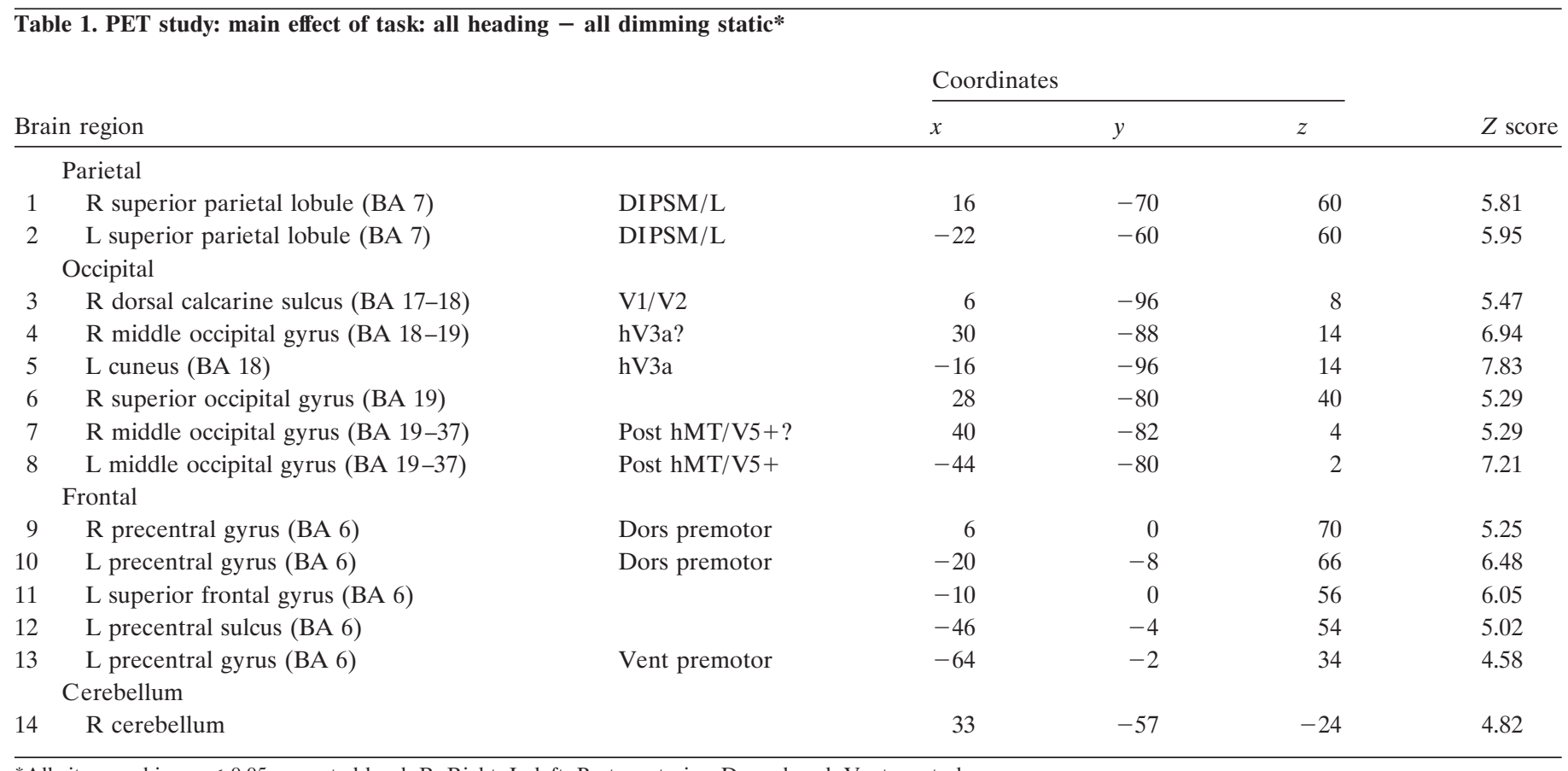

*All sites reaching $p<0.05$ corrected level. R, Right; L, left; Post, posterior; Dors, dorsal; Vent, ventral.

Table 2. fMRI 1: local maxima of hMT/V5+ in two subtractions

\begin{tabular}{|c|c|c|c|c|c|c|c|c|}
\hline & \multicolumn{4}{|c|}{ Moving - stationary } & \multicolumn{4}{|c|}{ Heading - dimming static } \\
\hline & $x$ & $y$ & $z$ & $Z$ score & $x$ & $y$ & $z$ & $Z$ score \\
\hline \multirow[t]{2}{*}{ Subject 1} & 54 & -68 & 0 & 9.31 & 50 & -66 & -2 & 8.15 \\
\hline & -50 & -74 & 6 & 8.95 & -50 & -72 & 4 & 7.82 \\
\hline \multirow[t]{2}{*}{ Subject 2} & 48 & -60 & -4 & 8.32 & 48 & -62 & -4 & 6.52 \\
\hline & -52 & -66 & 6 & 8.16 & -50 & -64 & 4 & 6.16 \\
\hline \multirow[t]{2}{*}{ Subject 3} & 46 & -64 & 6 & 8.57 & 48 & -68 & 4 & 6.61 \\
\hline & -42 & -78 & 18 & 8.72 & -44 & -78 & 16 & 7.70 \\
\hline \multirow[t]{2}{*}{ Subject 4} & 58 & -60 & 2 & 8.00 & 58 & -60 & -2 & 5.80 \\
\hline & -44 & -74 & 0 & 8.67 & -46 & -76 & 0 & 7.72 \\
\hline \multirow[t]{2}{*}{ Median $(n=4)$} & 51 & -62 & 0 & 8.45 & 49 & -64 & -2 & 6.57 \\
\hline & -47 & -74 & 6 & 8.70 & -48 & -74 & 4 & 7.71 \\
\hline \multirow[t]{2}{*}{ Group $(n=4)$} & 48 & -66 & 0 & 8.85 & 48 & -63 & 3 & 8.70 \\
\hline & -45 & -72 & 3 & 8.78 & -45 & -75 & 6 & 8.52 \\
\hline
\end{tabular}

early visual areas (Mangun et al., 1993, 1997; Heinze et al., 1994; Mangun, 1995; Clark and Hillyard, 1996; Woldorff et al., 1996; Vandenberghe et al., 1997; Kastner et al., 1998; Tootell et al., 1998a), including even hMT/V5 + (Beauchamp et al., 1997), we found it important to disentangle spatial and featural attention effects in the heading network. Single-subject and group analysis $(n=4)$ of the replication of the original conditions (continuous heading-dimming static) again revealed a network, largely similar to that in the PET experiment (Fig. 4) and in the first fMRI experiment (data not shown), with early visual areas being activated in the occipital lobe, extending anteriorly, and including hMT/V5 bilaterally (Fig. 5, left panels). Right posterior parietal and dorsal premotor activation also was observed. The new subtraction (continuous heading - dimming flow) yielded significant differential activation (Fig. 5, middle panels) in only a subset of the regions that appeared in the initial subtraction. From the original, extensive, early visual activation in the dorsal occipital lobe, only a single left $\mathrm{V} 3 / \mathrm{V} 3 \mathrm{a}$ focus, $(-18,-93,15 ; Z=5.47)$ reached 0.05 corrected level in the new subtraction. The other "surviving" areas in the reduced network included right hMT/V5+ $(51,-63$, $-3 ; Z=4.99)$, right DIPSM/L $(24,-66,57 ; Z=5.77)$, and a right dorsal premotor area $(36,3,51 ; Z=5.39)$. Even in these surviving areas, spatial attention had an effect, as witnessed by the differences in MR signal between the two dimming control tasks (Fig. 5, right panels; see activity profiles). Finally, right lateral cerebellum (33, $-57,-24 ; Z=4.82$ ) (Fig. 5, top middle panel, arrow) also reached 0.05 corrected level in the new subtraction.

\section{fMRI 3: equating motor preparation}

The third fMRI study was set up to control for possible differences in response preparation between the heading and the control conditions in the previous fMRI experiment. The main effect of task (all heading-all dimming flow), in which motor responses were exactly matched, yielded activation sites similar to 

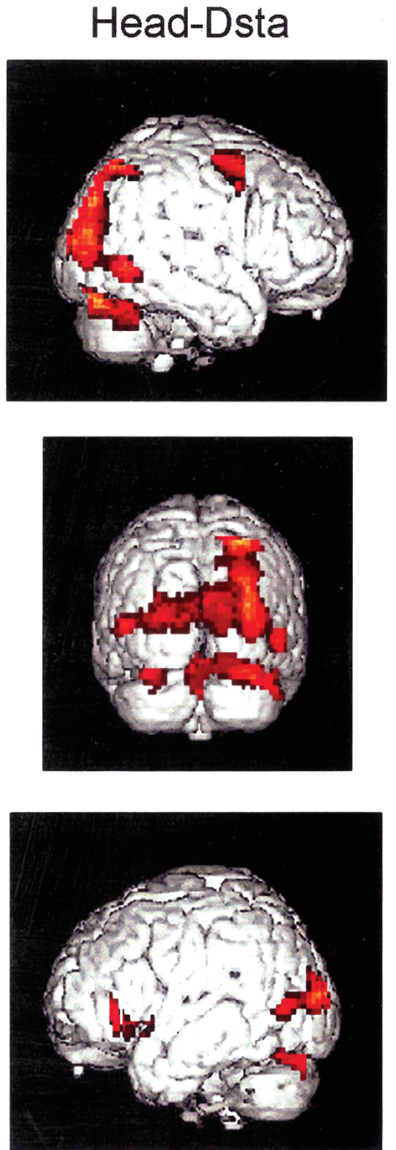

level in heading - dimming flow. Same conventions as Figure 4. Arrow points to cerebellar activation. Dflo, Dimming flow.
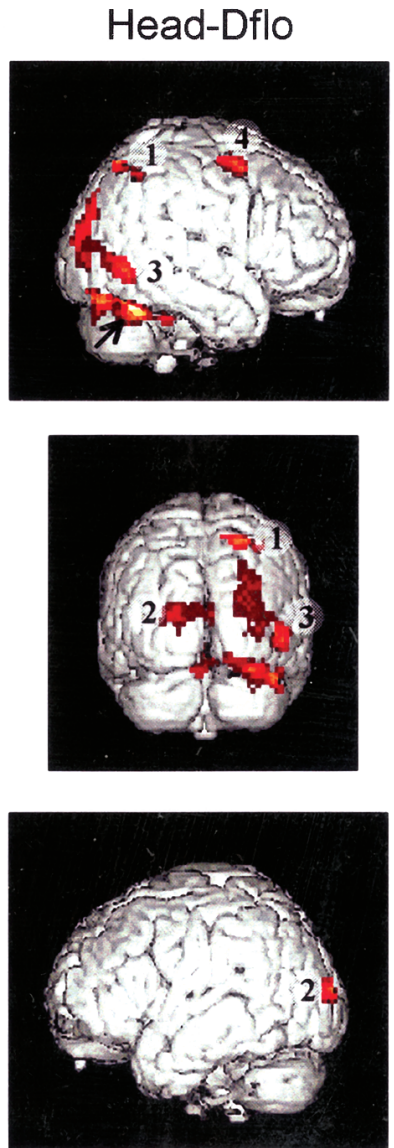

3.09

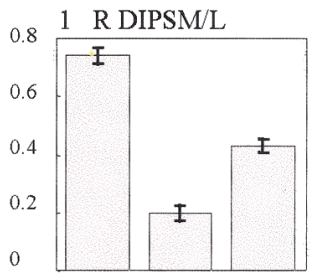

$2 \mathrm{LhV} 3 / \mathrm{V} 3 \mathrm{a}$

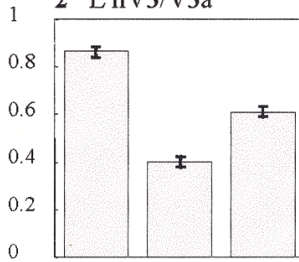

3 RhMT/V5+

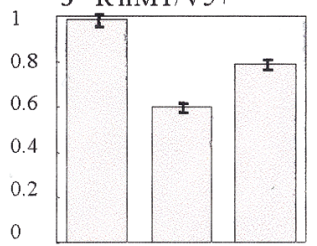

4 R dors Premotor

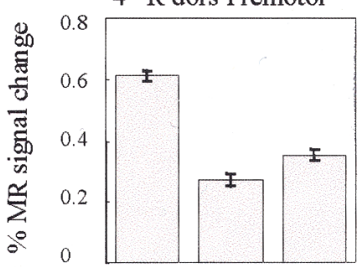

Head Dsta Dflo the results of fMRI2 (Fig. 6, Table 3). Significant activation was observed bilaterally in DIPSM/L $(18,-69,63 ; Z=7.2$; and -21 , $-63,60 ; Z=6.25)$ and adjacent regions, as well as in precentral areas $(30,-3,57 ; Z=5.10$; and $21,3,69 ; Z=4.70)$, demonstrating that DIPSM/L and dorsal premotor regions were not simply involved in motor response generation. In left hMT/V5+, two local maxima $(-42,-72,-3 ; Z=6.17$; and $-51,-63,6 ; Z=$ $5.17)$ were close to the local maximum defined in the motionlocalizing scans $(-45,-66,0)$. Three sites near the right hMT/ $\mathrm{V} 5+$ area $(42,-75,24 ; Z=6.43 ; 54,-63,-15 ; Z=4.90$; and 48 , $-57,12 ; Z=6.46)$ were located on the edges of the motionresponsive region defined in the localizing scans (local maximum at $54,-63,-3)$. None of the early visual areas showed significant differential activation in this subtraction, confirming the result of the previous fMRI experiment. A left middle occipital site and two sites in or close to the ventral part of the intraparietal sulcus bilaterally also reached significance.

The main effect of the motor manipulation (press left or right key vs pressing both keys) yielded one activation site $(9,-75,15$; $Z=5.13$ ), and its inverse (pressing both keys vs pressing left or right) yielded only two ( $-33,-87,27 ; Z=6.13$; and $42,-87,-9$; $Z=5.09$ ) significant foci in the occipital lobe. No parietal or frontal regions were differentially activated in these subtractions, indicating that not only motor execution but also motor preparation were relatively equal in the two motor conditions. This latter is not totally surprising because the paradigm, a two-alternative forced choice, was the same in the two motor conditions. The interactions between task and motor response reached significance only after conjunction with the main effect of heading. The interaction of the heading task and pressing both keys (Table 4) yielded significant activation close to regions involved in the main effect of heading (Table 3). An example was DIPSM/L (15, -66, $-66 ; Z=6.10$ ), as shown in its activity profile (Fig. 6, $1 R$ DIPSM/L): the difference between heading and control task was larger for both keys/no response than for $\mathrm{L} / \mathrm{R}$ responses. Other such sites included right middle temporal gyrus $(51,-57,9 ; Z=$ $5.33)$ and right precentral gyrus $(30,-3,60 ; Z=5.11)$. The other interaction sites were located in right middle and lateral occipital cortex (Table 4).

\section{Conjunction analysis}

A conjunction between heading effects of studies fMRI2 and fMRI3 was made by calculating an average image per condition and per session. This analysis uses the power of a larger subject group but keeps the specificity of the original subtractions, including the main effect of heading in fMRI3. It yields the network involved in heading compared with detection of the dimming of the flow dots, in intermittent and continuous flow conditions and regardless of motor response type. In addition, it represents a more stringent analysis, and significance levels are reduced in comparison to results of the standard group analysis. This conjunction analysis confirms that the most important nodes of the heading network are the right $\mathrm{hMT} / \mathrm{V} 5+$ region and right DIPSM/L, which reached $p<0.05$ corrected level, whereas bilateral premotor regions and left hMT/V5+ and left DIPSM/L are weakly activated ( $p<0.001$ uncorrected) (Fig. 7). A similar conjunction analysis for the motion localizer scans confirmed that the right posterior parietal region (Fig. 7, 2) indeed corresponds 

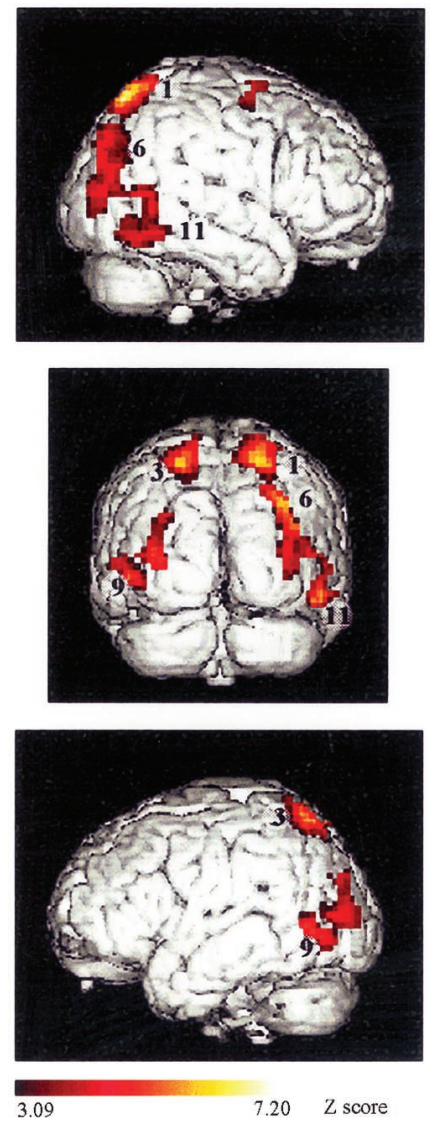

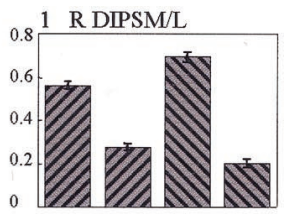

\section{L DIPSM/L}
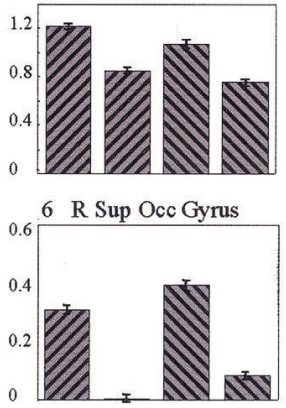

9 LhMT/V5+
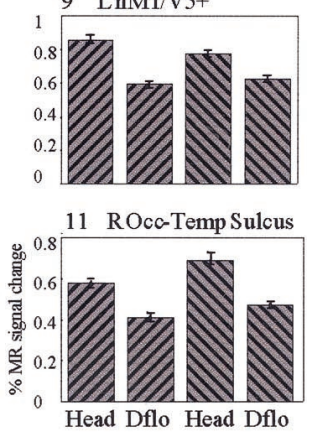

Figure 6. Results of fMRI3. Left panels, Rendered image of voxels reaching $p<0.001$ (see color code) in the main effect of task (all heading-all dimming flow). Right panels, Activity profiles in percentage adjusted MR signal change relative to fixation of five sites. Numbers correspond to regions listed in Table 3. Hatching: /// indicates left/right

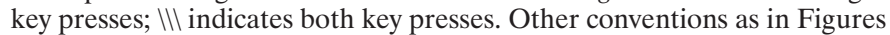
4 and 5.

to the motion-responsive DIPSM/L region, but that the right $\mathrm{hMT} / \mathrm{V} 5$ activation in heading is somewhat ventral to the motion activation, overlapping in an inferior satellite of hMT/V5 (57, $-63,-15)$ (Fig. 7, 1).

\section{Single-subject analysis}

To document the range of activation patterns in individual subjects, we analyzed the activation of the right inferior hMT/V5, the right DIPSM/L, and the right dorsal premotor region in each of the nine subjects participating in fMRI2 and fMRI3. For each site, we searched each subject's SPM for a local maximum, significant at $p<0.001$ uncorrected, located within $15 \mathrm{~mm}$ of the group coordinates (see above). The activity in these local maxima, given as a percentage of the fixation response, is plotted in Figure 8 for right inferior MT/V5+ (nine subjects), right DIPSM/L (eight subjects), and right premotor cortex (seven subjects). In all subjects the three main regions were consistently more activated during heading than during detection of the dimming of flow dots. The average location of these individual maxima matched the coordinates of the conjunction analysis (see above) quite well: 53, -59, -12 (SD 7, 5, 8; range, 18, 14, $26 \mathrm{~mm}$ ) for the right inferior MT/V5+; 21, $-63,63$ (SD 4, 5, 6; range, 15, 18, $17 \mathrm{~mm}$ ) for the right DIPSM/L; and 31, 3, 62 (SD 7, 7, 7; range, $22,22,16 \mathrm{~mm}$ ) for the right dorsal premotor region.

\section{DISCUSSION}

Using a very simple heading task and controlling visual input, visuospatial attention, motor preparation, and response as well as difficulty level, we observed featural effects in only two of the many motion-responsive regions of human cortex: human MT/ $\mathrm{V} 5+$ and its satellites and a posterior region in dorsal IPS. These human results suggest possible homologs for monkey MSTd and $7 \mathrm{a}$, which have been implicated in heading perception. In addition to these motion-responsive regions, dorsal premotor cortex was also specifically involved, which may reflect the linking of heading information to motor plans.

\section{Design issues}

The stimulus simulated a ground plane, optic flow field like that caused by simple forward translation of the observer. However, this random dot ground plane stimulus represents a marked abstraction from real life flow fields in which persisting objects can be tracked and show size changes, occlusion effects, and parallax differences ( $\mathrm{Li}$ and Warren, 2000). In the present stimulus, the most important cue to heading judgements was the distribution of the velocity vectors, which has been shown to be sufficient for the perception of heading (Warren et al., 1991; Dyre and Andersen, 1997). Furthermore, the stimulus was designed to induce subjects to use the global motion pattern instead of local motion cues. A control psychophysical experiment confirmed that our efforts had succeeded. Subjects fixated centrally while performing the heading task and no eye or head movements were allowed. This again entails a simplification of everyday life experience, which usually involves information from eye movements (Regan et al., 1982; Royden et al., 1992), neck proprioception, and the vestibular system (Crowell et al., 1998), but allowed for strict control of the experimental conditions and of the subjects' behavior. Not only were retinal input and oculomotor behavior kept identical in the two tasks to be compared, but performance levels were also equalized, leaving only the difference in the nature of the tasks to account for any observed activation.

As noted before, the continuous flow conditions, but not the intermittent flow conditions, contain a potential confound: the turning of some dots at the onset of the FOE shift. This factor did not affect our observations because the PET study failed to show interaction between the type of flow and the task effect, and the network for heading yielded by the conjunction analysis of the fMRI data applies to the two types of flow conditions.

\section{Human MT/V5+}

hMT/V5 + was effectively recruited by attention to heading. In the initial PET and fMRI experiment, the experimental and control conditions differed in terms of both featural attention, because subjects attended to different aspects (flow and luminance) in the stimulus, and visuospatial attention, because subjects attended to different positions (lower and upper field) in the stimulus configuration. Although both factors indeed contributed to the hMT/V5+ activation, the featural attention effect was significant on its own, as was demonstrated by matching visuospatial attention in heading and control tasks in the last two fMRI experiments. That hMT/V5+ activity depends on both featural attention and visuospatial attention is in agreement with Beauchamp et al. (1997) and Tootell et al. (1998a).

Interestingly, the main occipitotemporal region involved in featural attention to the optic flow pattern was not hMT/V5 proper but a more ventral region, which we have referred to as the inferior satellite. This latter region is close to the fusiform acti- 


\begin{tabular}{|c|c|c|c|c|c|c|}
\hline & & & \multicolumn{3}{|c|}{ Coordinates } & \multirow[b]{2}{*}{$Z$ score } \\
\hline \multicolumn{3}{|c|}{ Brain region } & $x$ & $y$ & $z$ & \\
\hline \multicolumn{7}{|c|}{ Parietal } \\
\hline 1 & R superior parietal lobule (BA 7) & DIPSM/L & 18 & -69 & 63 & 7.20 \\
\hline 2 & & & 24 & -60 & 69 & 5.95 \\
\hline 3 & L superior parietal lobule (BA 7) & DIPSM/L & -21 & -63 & 60 & 6.25 \\
\hline 4 & & & -12 & -60 & 66 & 5.63 \\
\hline 5 & & & -12 & -57 & 57 & 4.83 \\
\hline \multicolumn{7}{|c|}{ Occipital } \\
\hline 6 & R superior occipital gyrus (BA 19) & & 36 & -78 & 36 & 7.07 \\
\hline 7 & L superior occipital gyrus (BA 19) & & -30 & -81 & 30 & 4.68 \\
\hline 8 & L middle occipital gyrus (BA 19) & & -36 & -78 & 9 & 4.71 \\
\hline 9 & L inferior temporal sulcus (BA 37) & $\mathrm{hMT} / \mathrm{V} 5+$ & -42 & -72 & -3 & 6.17 \\
\hline 10 & & $\mathrm{hMT} / \mathrm{V} 5+$ & -51 & -63 & 6 & 5.17 \\
\hline 11 & R occipitotemporal sulcus (BA 37) & Inf hMT/V5+ & 54 & -63 & -15 & 4.90 \\
\hline \multirow[t]{2}{*}{12} & $\mathrm{R}$ asc limb inf temporal sulcus (BA 19) & Post hMT/V5+ & 42 & -75 & 24 & 6.43 \\
\hline & Temporal & & & & & \\
\hline \multirow[t]{2}{*}{13} & R middle temporal gyrus (BA 39) & Ant to hMT/V5+? & 48 & -57 & 12 & 6.46 \\
\hline & Frontal & & & & & \\
\hline 14 & R precentral sulcus (BA 6) & Dorsal premotor & 30 & -3 & 57 & 5.10 \\
\hline 15 & R superior frontal gyrus (BA 6) & & 21 & 3 & 69 & 4.70 \\
\hline
\end{tabular}

*All sites reaching $p<0.05$ corrected level in the main effect. R, Right; L, left; Inf, inferior; Post, posterior; Ant, anterior.

\begin{tabular}{|c|c|c|c|c|c|}
\hline \multicolumn{6}{|c|}{ 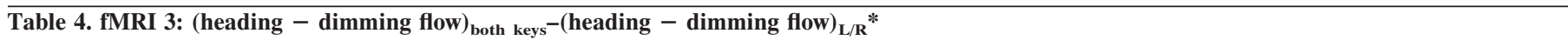 } \\
\hline \multirow[b]{2}{*}{ Brain region } & & \multicolumn{3}{|c|}{ Coordinates } & \multirow[b]{2}{*}{$Z$ score } \\
\hline & & $x$ & $y$ & $z$ & \\
\hline \multicolumn{6}{|l|}{ Parietal } \\
\hline \multirow[t]{2}{*}{ R superior parietal lobule (BA 7) } & $\mathrm{DIPSM} / \mathrm{L}$ & 15 & -66 & 66 & 6.10 \\
\hline & & 27 & -66 & 54 & 5.35 \\
\hline \multicolumn{6}{|l|}{ Occipital } \\
\hline R middle occipital gyrus (BA 19) & & 30 & -81 & 30 & 5.21 \\
\hline R lateral occipital cortex (BA 19) & Posterior hMT/V5+ & 48 & -75 & 15 & 5.19 \\
\hline \multicolumn{6}{|l|}{ Temporal } \\
\hline $\mathrm{R}$ middle temporal gyrus (BA 39) & Anterior hMT/V5+ & 51 & -57 & 9 & 5.33 \\
\hline \multicolumn{6}{|l|}{ Frontal } \\
\hline R precentral sulcus (BA 6) & Dorsal premotor & 30 & -3 & 60 & 5.11 \\
\hline
\end{tabular}

*All sites reaching $p<0.05$ corrected level, after conjunction with (all heading-all dimming flow). R, Right; L, left.

vation observed by De Jongh et al. (1994) when subjects viewed passively expanding flow fields compared with random velocity vectors. However, the fusiform activation in the latter study was bilateral, whereas the heading activation in the present study was in the right hemisphere. The same inferior satellite is involved in passive processing of structure from motion, at least for surfaces defined by moving dots (Sunaert et al., 2000). In monkey MSTd, neurons have been reported to be selective not only for optic flow patterns but also for speed gradients (Duffy and Wurtz, 1997; Sugihara et al., 1998). Thus the inferior satellite is a potential human homolog of monkey MSTd. Others have suggested that hMT/V5 + proper includes the homolog of MST (DeYoe et al., 1996; Tootell et al., 1998b). According to this alternative, the inferior satellite might correspond to more ventral motion regions in the monkey STS (Vanduffel et al., 2000), such as the FST (Desimone and Ungerleider, 1986) or posterior STP region (Oram and Perrett, 1994; Anderson and Siegel, 1999).

\section{Dorsal intraparietal sulcus}

A next area consistently activated in all comparisons between heading and control tasks was DIPSM/L in the posterior portion of the IPS. Sunaert et al. (1999) reported motion sensitivity in a number of parietal regions, including DIPSM and DIPSL. In the present study as in the previous, these two activation sites were difficult to separate. Cornette et al. (1998) reported activation along the dorsal lips of the intraparietal sulcus in fine-direction discrimination compared with a control task similar to that used here. Shulman et al. (1999) reported that the posterior IPS is involved in the encoding of directional instructions. Using a different experimental paradigm, Büchel et al. (1998) also described activation in this posterior parietal region when their subjects expected a speed change in an expanding motion stimulus. Compared with the above-mentioned studies, the present DIPSM/L activation was more restricted, suggesting that this parietal region might be more specifically tuned to heading esti- 

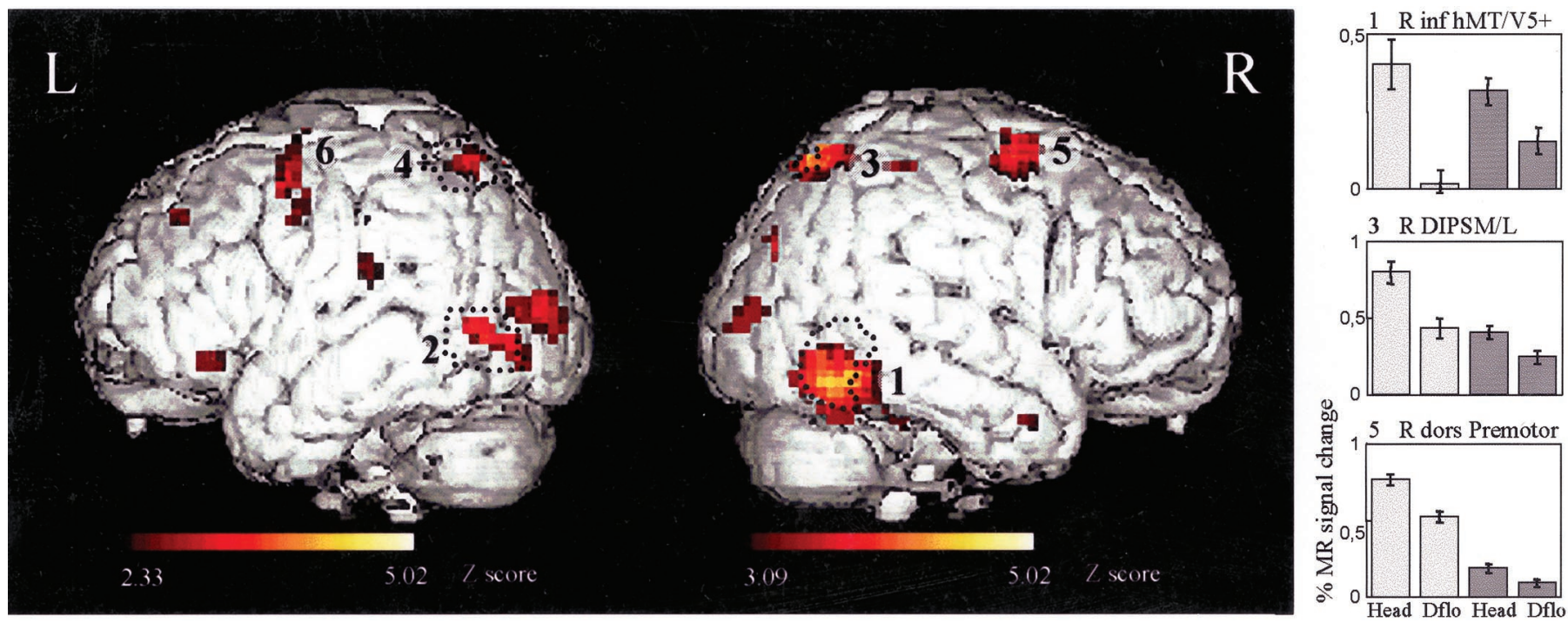

Figure 7. Rendered image (left and right lateral views in left and middle panels) of voxels reaching $p<0.001$ (right) or $p<0.01$ (left) in the conjunction of the main effects of task (heading-dimming flow) in fMRI2 and fMRI3 (conjunction analysis) with corresponding activity profiles (right panels): 1, hMT/V5+; 2, DIPSM/L; 3, dorsal premotor area. Small black dots outline areas hMT/V5+ and DIPSM/L from motion localizer scans (conjunction analysis; $p<0.001$ for right side, $p<0.01$ for left side). The activity profiles plot the percentage change in MR signals with respect to fixation in heading and dimming flow of fMRI2 (light gray bars) and heading and dimming flow, averaged over the two motor conditions of fMRI3 (dark gray bars). Notice that the conjunction probes only the difference between heading and control in the two experiments. Sites reaching $p<0.05$ corrected level for heading: right DIPSM/L $(24,-63,60 ; Z=5.03)$, right inferior hMT/V5 + $(51,-51,-15 ; Z=4.87$; and $54,-63,-18 ; Z=4.54)$; sites reaching $p<0.001$ uncorrected: bilateral dorsal premotor $(-21,-3,54 ; Z=4.43$; and $30,0,60 ; Z=4.38)$ and left hMT/V5+ $(-45,-75,-3 ; Z=3.38)$ left DIPSM/L $(-21,-60,57 ; Z=3.30)$. Coordinates of motion responsive regions: right hMT/V5+ $(51,-60,-3 ; Z=4.84)$ and inferior satellite $(57,-63,-15 ; Z=$ 4.74), left hMT/V5+ $(-57,-60,3 ; Z=5.02)$ and $(-45,-72,0 ; Z=4.11)$, right DIPSM/L $(24,-60,54 ; \mathrm{z}=3.82)$ and left DIPSM/L $(-27,-60,-54$; $Z=4.25)$.

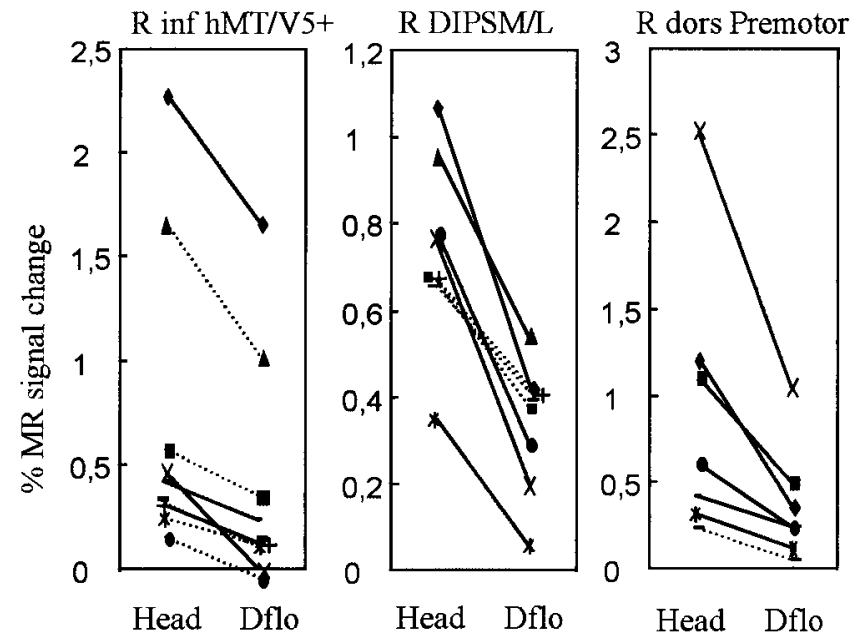

Figure 8. Individual responses in the three main regions of the right hemisphere: inferior satellite of hMT/V5+ (left), DIPSM/L (middle), and dorsal premotor region (right). The percentage signal change with respect to fixation in heading ( Head) and dimming flow (Dflo) is plotted for the nine subjects participating in fMRI2 and fMRI3. Only data from subjects in which a site located within $15 \mathrm{~mm}$ of the group activation (conjunction analysis, Fig. 7) reached $p<0.001$ uncorrected (dotted lines) or $p<0.05$ corrected ( full lines) in the subtraction heading - dimming flow (fMRI2) or the main effect of heading - dimming flow (fMRI3) were included.

mation compared with other parietal motion areas. The present activation of DIPSM/L in heading is consistent with patient studies. Vaina and colleagues (Jornales et al., 1997; Vaina, 1998) described two patients suffering from Balint syndrome with bilateral occipitoparietal lesions who performed well on low-level motion tasks but were strongly impaired on heading tasks as well as in a number of other high-level motion tasks.

If DIPSM/L plays such a role in motion processing, then it might be comparable with that of primate area $7 \mathrm{a}$, which is believed, on the basis of its connectivity, to be at the apex of the motion processing pathway. In area 7a, neurons selective for expansion/contraction were first described by Sakata et al. (1985). Siegel and Read (1997a) reported neurons with properties similar to those in MSTd, but they also documented angle-of-gaze and center-of-motion dependencies and speed selectivity. These authors concluded that this area might be involved in the extrapersonal representation of space and in the representation of self and object motion (Read and Siegel, 1997; Siegel and Read, 1997b; Phinney and Siegel, 2000).

Following a different approach, a number of authors have linked dorsal intraparietal sulcus regions to the control of visuospatial attention (Corbetta et al., 1993, 2000; Vandenberghe et al., 1996, 1997, 2000; Nobre et al., 1997; Hopfinger et al., 2000). In fMRI 2 and fMRI 3 of the present study, the dorsal intraparietal sulcus activation clearly survived elimination of sustained visuospatial attention differences between experimental and control conditions. Nevertheless, it may have been possible that in the heading task automatic but specific shifts in spatial attention toward the focus of expansion occurred on a trial to trial basis. These hypothetical shifts would have coincided completely with optic flow processing and therefore would not have been eliminated from the paradigm. Such shifts, however, were at least as likely in the dimming static control condition. Because the DIPSM/L activation was present in comparisons of heading with both dimming static and dimming flow (fMRI2), it is unlikely that shifts of attention explain the DIPSM/L activation.

Finally, the DIPSM/L activation may be related to motor 
response generation. Although the number of key presses in the tasks was equal, motor planning (pressing left/right vs pressing both keys) was clearly different in the initial experiments. Because motor intention is encoded in posterior parietal cortex in primates (Andersen et al., 1997; Snyder et al., 1998, 2000), a motor preparation effect could not be excluded in any but the third fMRI experiment. The DIPSM/L activation survived the matching of motor response planning in this last fMRI experiment, indicating that it could not be explained on the basis of a motor response difference; however, it may reflect decision-related processes. There is growing evidence from single-cell studies for the involvement of parietal cortex in decision processes (Shadlen and Newsome, 1996; Platt and Glimcher, 1999).

\section{Premotor activation}

Finally, dorsal premotor activity was consistently stronger in the heading task than in the control tasks. The effect was not caused by a difference in motor response preparation per se, because matching the motor responses between conditions in the last fMRI experiment did not eliminate this activation (Table 3). These results are in line with primate studies indicating that premotor neuronal activity is affected not only by the action to be taken, but also by events guiding that action (Boussaoud and Wise, 1993; Wise et al., 1997). Thus, expanding on the considerations on DIPSM/L, dorsal premotor activation might be thought of as a final stage in a parieto-premotor visuomotor connection, specifically related to transformation of heading information, extracted in hMT/V5+ and DIPSM/L, into motor schemes.

\section{REFERENCES}

Andersen RA, Asanuma C, Essick GK, Siegel RM (1990) Corticocortical connections of anatomically and physiologically defined subdivisions within inferior parietal lobule. J Comp Neurol 296:65-113.

Andersen RA, Snyder LH, Bradley DC, Xing J (1997) Multimodal representation of space in the posterior parietal cortex and its use in planning movements. Annu Rev Neurosci 20:303-330.

Anderson KC, Siegel RM (1999) Optic flow selectivity in the anterior superior temporal polysensory area, STPa, of the behaving monkey. J Neurosci 19:2681-2692.

Baizer JS, Ungerleider LG, Desimone R (1991) Organization of visual inputs to the inferior temporal and posterior parietal cortex in macaques. J Neurosci 11:168-190.

Beauchamp MS, Cox RW, DeYoe EA (1997) Graded effects of spatial and featural attention on human area MT and associated motion processing areas. J Neurophysiol 78:516-520.

Boussaoud D, Wise SP (1993) Primate frontal cortex: effects of stimulus and movement. Exp Brain Res 95:28-40.

Boussaoud D, Ungerleider LG, Desimone R (1990) Pathways for visual motion analysis: cortical connections of the medial superior temporal and the fundus of the superior temporal visual areas in the macaque. J Comp Neurol 269:462-495.

Bradley DC, Maxwell M, Andersen RA, Banks MS, Shenoy KV (1996) Mechanisms of heading perception in primate visual cortex. Science 273:1544-1547.

Britten KJ, van Wezel RJ (1998) Electrical microstimulation of cortical area MST biases heading perception in monkeys. Nat Neurosci $1: 59-63$.

Büchel C, Josephs O, Rees G, Turner R, Frith CD, Friston KJ (1998) The functional anatomy of attention to visual motion. A functional MRI study. Brain 121:1281-1294.

Clark VP, Hillyard SA (1996) Spatial selective attention affects early extrastriate but not striate components of the visual evoked potential. J Cogn Neurosci 8:387-402.

Corbetta M, Miezin FM, Shulman GL, Petersen SE (1993) A PET study of visuospatial attention. J Neurosci 13:1202-1226.

Corbetta M, Kincade JM, Ollinger JM, McAvoy MP, Shulman GL (2000) Voluntary orienting is dissociated from target detection in human posterior parietal cortex. Nat Neurosci 3:292-297.

Cornette L, Dupont P, Rosier A, Sunaert S, Van Hecke P, Michiels J, Mortelmans L, Orban GA (1998) Human brain regions involved in direction discrimination. J Neurophysiol 79:2749-2765.

Crowell JA, Banks MS, Shenoy KV, Andersen RA (1998) Visual selfmotion perception during head turns. Nat Neurosci 1:732-737.

De Jongh BM, Shipp S, Skidmore B, Frackowiak RSJ, Zeki S (1994) The cerebral activity related to the visual perception of forward motion in depth. Brain 117:1039-1054.

Desimone R, Ungerleider LG (1986) Multiple visual areas in the caudal superior temporal sulcus of the macaque. J Comp Neurol 248:164-189.

DeYoe EA, Carman GJ, Bandettini P, Glickman S, Wieser J, Cox R, Miller D, Neitz J (1996) Mapping striate and extrastriate visual areas in human cerebral cortex. Proc Natl Acad Sci USA 93:2382-2386.

Dubner R, Zeki SM (1971) Response properties and receptive fields of cells in an anatomically defined region of the superior temporal sulcus in the monkey. Brain Res 35:528-532.

Duffy CJ, Wurtz RH (1991) Sensitivity of MST neurons to optic flow stimuli. I. A continuum of response selectivity to large field stimuli. J Neurophysiol 65:1329-1345.

Duffy CJ, Wurtz RH (1997) Medial superior temporal area neurons respond to speed patterns in optic flow. J Neurosci 17:2839-2851.

Dupont P, Orban GA, Vogels R, Bormans G, Nuyts J, Schiepers C, De Roo M, Mortelmans L (1993) Different perceptual tasks performed with the same visual stimulus attribute activate different regions of the human brain: a positron emission tomography study. Proc Natl Acad Sci USA 90:10927-10931.

Dupont P, Orban GA, De Bruyn B, Verbruggen A, Mortelmans L (1994) Many areas in the human brain respond to visual motion. J Neurophysiol 72:1420-1424.

Dyre BP, Andersen GJ (1997) Image velocity magnitudes and perception of heading. J Exp Psychol Hum Percept Perform 23:546-565.

Engel SA, Glover GH, Wandell BA (1997) Retinotopic organization in human visual cortex and the spatial precision of functional MRI. Cereb Cortex 7:181-192.

Fox PT, Mintum MA, Raichle ME, Miezin FM, Allman JM, Van Essen DC (1986) Mapping human visual cortex with positron emission tomography. Nature 323:806-809.

Gibson JJ, Olum P, Rosenblatt F (1955) Parallax and perspective during aircraft landings. Am J Psychol 68:372-385.

Graziano MS, Andersen RA, Snowden RJ (1994) Tuning of MST neurons to spiral neurons. J Neurosci 14:54-67.

Heinze HJ, Mangun GR, Burchert W, Hinrichs H, Scholz M, Munte TF, Gos A, Scherg M, Johannes S, Hundeshagen H (1994) Combined spatial and temporal imaging of brain activity during visual selective attention in humans. Nature 372:543-546.

Hopfinger JB, Buonocore MH, Mangun GR (2000) The neural mechanisms of top-down attentional control. Nat Neurosci 3:284-291.

Jornales VE, Jakob M, Zamani A, Vaina LM (1997) Deficits on complex motion perception, spatial discrimination and eye-movements in a patient with bilateral occipital-parietal lesions. Invest Ophthalmol Vis Sci 38:S72.

Kastner S, De Weerd P, Desimone R, Ungerleider LG (1998) Mechanisms of directed attention in the human extrastriate cortex as revealed by functional MRI. Science 282:108-111.

Lagae L, Maes H, Raiguel S, Xiao D-K, Orban GA (1994) Responses of macaque STS neurons to optic flow components: a comparison of areas MT and MST. J Neurophysiol 71:1597-1626.

Lappe M, Bremmer F, Pekel M, Thiele A, Hoffmann KP (1996) Optic flow processing in monkey STS: a theoretical and experimental approach. J Neurosci 16:6265-6285.

Li L, Warren WH (2000) Perception of heading during rotation: sufficiency of dense motion parallax and reference objects. Vision Res 40:3873-3894.

Mangun GR (1995) Neural mechanisms of visual selective attention. Psychophysiology 32:4-18.

Mangun GR, Hillyard SA, Luck SJ (1993) Electrocortical substrates of visual selective attention. In: Attention and performance XIV (Meyer D, Kronblum S, eds), pp 219-244. Cambridge, MA: MIT.

Mangun GR, Hopfinger J, Kussmaul CL, Fletchert E, Heinze HJ (1997) Covariations in ERP and PET measures of spatial selective attention in human extrastriate visual cortex. Hum Brain Mapp 5:273-279.

Nobre AC, Sebestyen GN, Gitelman DR, Mesulam MM, Frackowiak RS, Frith CD (1997) Functional localization of the system for visuospatial attention using positron emission tomography. Brain 120:515-533.

Oram MW, Perrett DI (1994) Responses of anterior superior temporal polysensory (STPa) neurons to "biological motion" stimuli. J Cogn Neurosci 6:99-116.

Orban GA, Vogels R (1998) The neuronal machinery involved in successive orientation discrimination. Prog Neurobiol 55:117-147.

Orban GA, Lagae L, Verri A, Raiguel S, Xiao D, Maes H, Torre V (1992) First-order analysis of optical flow in monkey brain. Proc Natl Acad Sci USA 89:2595-2599.

Phinney RE, Siegel RM (2000) Speed selectivity for optic flow in area 7a of the behaving macaque. Cereb Cortex 10:413-421.

Platt ML, Glimcher PW (1999) Neural correlates of decision variables in parietal cortex. Nature 400:233-238.

Price CJ, Friston KJ (1997) Cognitive conjunction: a new approach to brain activation experiments. NeuroImage 5:261-270.

Read HL, Siegel RM (1997) Modulation of responses to optic flow in area $7 \mathrm{a}$ by retinotopic and oculomotor cues in monkey. Cereb Cortex 7:647-661. 
Regan D, Beverly KD (1982) How do we avoid confounding the direction we are looking and the direction we are moving? Science 215:194-196.

Royden CS, Hildreth EC (1999) Differential effects of shared attention on perception of heading and 3-D object motion. Percept Psychophys 61:120-133.

Royden CS, Banks MS, Crowell JA (1992) The perception of heading during eye movements. Nature 360:583-585.

Saito H, Yukie M, Tanaka K, Hikosaka K, Fukada Y, Iwai E (1986) Integration of direction signals of motion in the superior temporal sulcus of the macaque monkey. J Neurosci 6:145-157.

Sakata H, Shibutani H, Kawano K, Harrington TL (1985) Neural mechanisms of space vision in the parietal association cortex of the monkey. Vision Res 25:453-463.

Schaafsma SJ, Duysens J (1996) Neurons in the ventral intraparietal area of the awake macaque monkey closely resemble neurons in the dorsal part of the medial superior temporal area in their responses to optic flow patterns. J Neurophysiol 76:4056-4068.

Sereno MI, Dale AM, Reppas JB, Kwong KK, Belliveau JW, Brady TJ, Rosen BR, Tootell RB (1995) Borders of multiple visual areas in humans revealed by functional magnetic resonance imaging. Science 268:889-893.

Shadlen MN, Newsome WT (1996) Motion perception: seeing and deciding. Proc Natl Acad Sci USA 93:628-633.

Shulman GL, Ollinger JM, Akbudak E, Conturo TE, Snyder AZ, Petersen SE, Corbetta M (1999) Areas involved in encoding and applying directional expectations to moving objects. J Neurosci 19:9480-9496.

Siegel RM, Read HL (1997a) Analysis of optic flow in the monkey parietal area 7a. Cereb Cortex 7:327-346.

Siegel RM, Read HL (1997b) Construction and representation of visual space in the inferior parietal lobule. In: Cereb cortex, Vol 12: Extrastriate cortex in primates (Rockland KS, Kaas JH, Peters A, eds), pp 499-525. New York: Plenum.

Snyder LH, Batista AP, Andersen RA (1998) Change in motor plan, without a change in the spatial locus of attention, modulates activity in the posterior parietal cortex. J Neurophysiol 79:2814-2819.

Snyder LH, Batista AP, Andersen RA (2000) Intention-related activity in the posterior parietal cortex: a review. Vision Res 40:1433-1441.

Sugihara H, Murakami I, Komatsu H, Shenoy KV, Andersen RA (1998) Selectivity of neurons to the 3D orientation of a rotating plane in area MSTd of the monkey. Soc Neurosci Abstr 24:649.

Sunaert S, Van Hecke P, Marchal G, Orban GA (1999) Motion responsive regions in the human brain. Exp Brain Res 127:355-370.

Sunaert S, Van Hecke P, Marchal G, Orban GA (2000) Attention to speed of motion, speed discrimination, and task difficulty: an fMRI study. NeuroImage 11:612-623.
Talairach J, Tournoux P (1988) Co-planar stereotaxic atlas of the human brain. New York: Thieme.

Tootell RB, Reppas JB, Kwong KK, Malach R, Born RT, Brady TJ, Rosen BR, Belliveau JW (1995) Functional analysis of human MT and related cortical areas using magnetic resonance imaging. J Neurosci 15:3215-3230.

Tootell RB, Hadjikhani NK, Hall EK, Marrett S, Vanduffel W, Vaughan JY, Dale AM (1998a) The retinotopy of visuospatial attention. Neuron 21:1409-1422.

Tootell RB, Mendola JD, Hadjikhani NK, Liu AK, Dale AM (1998b) The representation of the ipsilateral visual field in human cerebral cortex. Proc Natl Acad Sci USA 95:818-824.

Vaina LM (1998) Complex motion perception and its deficits. Curr Opin Neurobiol 8:494-502.

Vandenberghe R, Dupont P, De Bruyn B, Bormans G, Michiels J, Mortelmans L, Orban GA (1996) The influence of stimulus location on the brain activation pattern in detection and orientation discrimination. A PET study of visual attention. Brain 119:1263-1276.

Vandenberghe R, Duncan J, Dupont P, Ward R, Poline JB, Bormans G, Michiels J, Mortelmans L, Orban GA (1997) Attention to one or two features in left or right visual field: a positron emission tomography study. J Neurosci 17:3739-3750.

Vandenberghe R, Duncan J, Arnell KM, Bishop SJ, Herrod NJ, Owen AM, Minhas PS, Dupont P, Pickard JD, Orban GA (2000) Maintaining and shifting attention within left or right hemifield. Cereb Cortex 10:706-713.

Vanduffel W, Beatse E, Nelissen K, Tootell RB, Todd JT, Orban GA (2000) Areas involved in extracting structure from motion: an fMRI study in the awake fixating monkey. Soc Neurosci Abstr 26:1583.

Warren WH, Kurtz KJ (1992) The role of central and peripheral vision in perceiving the direction of self motion. Percept Psychophys 51:443-454.

Warren WH, Morris MW, Kalish M (1988) Perception of translational heading from optical flow. J Exp Psychol Hum Percept Perform 14:646-660.

Warren WH, Blackwell AW, Kurtz KJ, Hatsopoulos NG, Kalish ML (1991) On the sufficiency of the velocity field for perception of heading. Biol Cybern 65:311-320.

Wise SP, Boussaoud D, Johnson PB, Caminiti R (1997) Premotor and parietal cortex: corticocortical connectivity and combinatorial computations. Annu Rev Neurosci 20:25-42.

Woldorff M, Fox P, Matzke M, Lancaster J, Veeraswamy S, Zamarripa F, Seabolt M, Glass T, Gao J, Martin C, Jerabek P (1996) Visual spatial attention: integration of PET and ERP data. NeuroImage 3:S242.

Zeki S, Watson JD, Lueck CJ, Friston KJ, Kennard C, Frackowiak RS (1991) A direct demonstration of functional specialization in human visual cortex. J Neurosci 11:641-649. 